\title{
How Dreams And Memory May Be Related
}

By

\author{
Eugen Tarnow \\ etarnow@avabiz.com (e-mail)
}

NEURO-PSYCHOANALYSIS

2003, Volume 5, Number 2

\begin{abstract}
:
I present a theory of dreams and long term memory structure that proposes that both entities are closely related. It is based on a variation of Freud's dream theory: (1) I re-label Freud's "Unconscious" the "Long Term Memory Structure” (LTMS), (2) I propose that dreams are ever present excitational responses to perturbations of perceptions and thought, during waking life as well as sleep, which only become conscious when the executive function of waking life ceases, and (3) I reinterpret Freud's "Dream Work" as describing the pre-dream Storage Transformation of perceptions and thought into the LTMS. I make one further conjecture: Memories are stored in the LTMS according to what is already in the LTMS. The observables of Freud's theory remain the same. The new theory is also consistent with recent experimental findings and suggests a partial basis for personality: the selection process of the Storage Transformation.
\end{abstract}


“... each of us remembers and forgets in a pattern whose labyrinthing windings are an identification mark no less distinctive than a fingerprint”

(American Pastoral, Philip Roth) 


\section{FREUD'S THEORY OF DREAMS}

Based on observations made by Freud and others in the last century (Freud, (1900) pp. 35-127), Freud describes a theory of dreams. The sequence of events transforming thought and perceptions into dreams is as follows (see Fig. 1 below and Freud, p. 638). Perceptions and thought from the day before the dream disturb the Unconscious. The Unconscious wants to express itself to the ego but is repressed by defense mechanisms until the time of dreaming. At the time of dreaming the defense mechanisms are lifted, leaving behind only a censor to scramble the Unconscious expressions. This censor accounts for the strangeness of dreams. The censor transformation is called "Dream Work" (p. 311). By studying dreams and their connection to the reality of the individual dreamers, Freud divided the Dream Work into condensation, displacement, the transformation of thought into visual images, and secondary revision. Freud proposed that by interpreting dreams, i.e. by reversing the Dream Work transformation, one could reveal the Unconscious, an important source of human personality.

A current review on dreams (Streich and Meier) mentions Freud's theory only superficially, illustrating the lack of relevance it is thought to have in much of today's experimental research on dreams. A current review on memory (Neath (1998)) does not mention Freud at all, illustrating the perceived lack of relevance of his work in the memory field. Recent work by Solms (1995, 1997a, 1997b, 1999) is again reviving interest in Freud's theory.

\section{PROPOSED THEORY AND A COMPARISON WITH FREUD'S THEORY}

In Fig. 2 I show the proposed theory of dreams and memory (the text in parenthesis in Fig. 2 indicates the corresponding structures of Freud's). I reinterprete Freud's "Unconscious" as the "Long Term Memory Structure" (LTMS). I reposition the "Dream Work" so that it takes place before perceptions and thought are stored in the LTMS and reinterpret it as a Storage Transformation. This Storage Transformation determines whether and how current thoughts and perceptions are eventually stored in the LTMS. I make the conjecture that memories are stored in the LTMS to a large extent according to what is already there, thus both the LTMS and the Storage Transformation change with time. Previous perceptions and thoughts are recalled via the Executive Interpretation Facility which communicates both with the LTMS and with current perceptions and thoughts to construct an acceptable recall. Dreams are reinterpreted as ever present LTMS Excitations which are consciously experienced only when the Executive Interpretation Facility is turned off. Repositioning the Dream Work does not affect, in any way, Freud's observables - dream reports, free associations, and recalled events - since from his observations, Freud could not tell whether the Dream Work took place before or after the dreaming. 
The present theory proposes that dreams and memory are closely connected and that the Storage Transformation is indicative of the real low-level memory function.

Let me give an example of how somebody would remember where he parked his car in a shopping mall according to the present theory. The driver drives around the mall, knows that the lanes are marked A, B, C, etc. and finds a spot in the $\mathrm{K}$ lane. He leaves the car and the event is transformed by the Storage Transformation into "sofa" and a picture of the letter "K" (using displacement and condensation). If asked, the driver's Executive Interpretation Facility, knowing that the driver is looking for his car in this particular parking lot, will later fill in that he parked his car (not a sofa) in the K lane of the shopping mall but in a later dream he may be sitting in his sofa staring at the letter $\mathrm{K}$.

\section{THE LTMS AND THE STORAGE TRANSFORMATION}

The LTMS is related to perceptions and thought via the Storage Transformation. The Storage Transformation consists of the set of rules of Freud of the "Dream Work": condensation, displacement, the transformation of thought into visual images, and secondary revision. The transformation is not necessarily one-to-one but more probably many-to-one. There is some support in the literature on memory for the many-to-one hypothesis: Squire proposed that those experiences induced by Penfield and Rasmussen that seemed familiar may have been the generic reconstructions of multiple, similar events rather than the evocation of a single actual event” (p. 80). Loftus \& Loftus (1980) also write that “[memory] reports may result from reconstruction of fragments of past experience or from constructions created at the time of report that bear little or no resemblance to past experience.”1

The LTMS is closely connected to the concept of "depth" processing in memory research. This concept holds that you will remember something better the "deeper" the encoding is. Thus memories encoded with "meaning” are predicted to be more easily remembered than memories encoded without. The problem in depth psychology is to find independent measures of "meaning" and "depth” (Neath, p. 115). The present theory provides such an independent measure: "meaningful” information is information with a high probability of surviving the Storage Transformation and "depth" is the number of subpieces of the information which survive the Storage Transformation. The greater the depth, the greater the probability that a recall by the Executive Interpretation Facility will be correct.

My conjecture from above: memories are stored into LTMS according to what is already there,

\footnotetext{
${ }^{1}$ Lofus \& Loftus classify the relationship between memory reports and the memorial information underneath as either "supplementation of nothing", coexistence or substitution. The one-to-many mapping is different from all of these and could be called "context dependent supplementation of something."
} 
has some support in research. A review by Leichtman and Ceci (1992) finds that “children's knowledge contributes quite directly to their ability to remember”. Indeed, perhaps somewhat trivial, materials can be learned easier if it had previously been already memorized (Ebbinghaus, (1885)). The conjecture results in a dynamically changing Storage Transformation and LTMS. It is plausible that the change takes place more rapidly at a young age: A gradual freezing of the LTMS would explain the primitiveness of dreams, especially if some of this freezing takes place before language starts to dominate our thoughts and perceptions. Freud's finding that all dreams fulfill the wishes of a young child is also consistent with an LTMS frozen in time sometime during childhood. Dreams in which we are embarrassed to be naked (p. 275), that our loved ones are dying (p. 281), and Freud's contention that all dreams are egoisting (p. 301) etc., and his contention that the sound of a word is much more important in dreams than the spelling (p. 441) also seem to be symptomatic of the mindset of a child (also see Zadra and Nielsen (1997) for a list of commonly experienced dreams, many of which seem to be concerns of a child). Freud concluded that understanding dreams of children, which are simpler, would help us understand dreams of adults. I suggest something more surprising: understanding adults dreams may reveal much about the mind of children. If that is indeed the case, it is not inconsistent that adults with more access to the memories of their childhood are also adults who remember more dreams, a correlation found by Schredl, Morlock, and Bozzer (1996).

An LTMS which becomes gradually frozen may partially account for our "personality": the criterion that new memories have to fit an old structure is a selection formula which over time could form a basis for relatively stable individual differences. Just how much of our personality can be derived from the LTMS can be experimentally measured by correlating personality test scores with memory retention scores. There might also be a correlation of the development of the Storage Transformation and stages of intellectual development.

\section{DREAMS AS EVER-PRESENT EXCITATIONS OF THE LTMS}

The LTMS is a dynamical system which, likely, cannot be turned off the moment after a perception or a thought has affected it but continues to be activated for some time. I identify dreams with these excitational responses of the LTMS. A similar proposition has earlier been made by Feinberg and March (1995) who write that it is possible that "an ongoing stream of mental activity persists throughout sleep as well as waking." The previously held dogma, that dreams are connected to REM sleep, has been challenged: It seems that length of dream recollection is correlated with arousal level which is in turn correlated with REM sleep; if we control for the arousal level, dream mentation is always taking place (Rosenlicht, Maloney and Feinberg (1994) and Feinberg and March (1995)). Cicogna, Cavallero and 
Bosellini (1986) suggest that cognitive processes "involved in the creation of original narrative sequences may be similar in sleep and waking." McCarley also observes that when asked to recall the last thought, people often report thoughts that are somewhat hallucinatory (quote in Foulkes and Fliesher, 1975, see also Breger, 1967, and Strauch and Meyer, and Foulkes, 1993)) and concludes:

The background cognitive content of personal concerns and feeling associations, which are not well organized verbally or reality tested, appears ready to become foreground whenever the level of voluntary control drops. This usually happens when the need to attend to the outside world is low.

Penfield and Rasmussen's excitation of the human cortex with an electrode probes the physical nature of human memory. In 4-7\% of their cases (as reviewed by Squire (1987)) the subjects report experiences similar to dreams dreams, not to perceptions or thought as they are regularly communicated:

if the electrode is held in place, action [in the brain as reported by the subjects] goes forward as in a dream and the patient may become frightened and cry out. . . . we have stumbled unexpectedly upon the location of the neuronal patterns "which dreams are made of" (p. 179).

Squire observes that elements of fantasy rather than memory sometimes appeared, as in hearing both halves of a telephone conversation. Squires reviews work done after Penfield and finds that frequency of elicited experiences were about the same and that the experiences were "hallucinated images or scenes, emotions, visceral sensations, or unformed sensation" and "memory-like hallucinations" were much more rare. He also reports that the experiences seemed connected to the subject's personality, also in accordance with the present theory.

One important property of dreams, and therefor of the LTMS, is the time distribution of the dream elements. If dreams are excitations, they should decay more rapidly than memory itself. Freud wrote that all manifest content comes from thoughts and perceptions of the day before the dream, the so called day residue. Recent statistics have proved him somewhat correct: the manifest content of dreams is derived mostly from events of the day before but it is also drawn from events as far back as more than a year. In particular, Strauch \& Meier (p. 164; see also Harlow, J. and Roll, S. (1992)) found the following data on the time distribution of dream elements:

\begin{tabular}{|l|l|}
\hline Temporal Sources of Dream Elements & \% of elements found per time interval \\
\hline People - last day & 67.6 \\
\hline
\end{tabular}




\begin{tabular}{|l|l|}
\hline People - last week & 19.7 \\
\hline People - last year & 7.0 \\
\hline Settings - last day & 42.9 \\
\hline Settings - last week & 31.4 \\
\hline Settings - last year & 14.3 \\
\hline Objects - last day & 52.2 \\
\hline Objects - last week & 31.4 \\
\hline Objects - last year & 14.3 \\
\hline
\end{tabular}

TABLE 1. (Strauch \& Meier)

We inquired as to the analytic shape of the time dependence of this data. For each class: people, settings, objects, a simple exponential decay does not suffice but an algebraic decay such that probability of inclusion in dream $\sim \mathrm{t}^{-1.7}$ to $\mathrm{t}^{-2.0}$ gives a better fit (see Fig. 3). The 1.7-2.0 algebraic decay can be contrasted with the savings data of Ebbinghaus (Fig. 4) which obey a much slower algebraic decay of 0.1. The time dependence found in a recent recall experiment decays with an initial algebraic exponent of about 0.3 which subsequently increases to about 0.5 . Thus dreams do decay faster than the LTMS.

The exact relation between dreams and the LTMS remains to be discovered. The words and pictures we obtain in dream reports are highly characteristic of our individual LTMS's. The reader can make a simple experiment to verify this: Find a friend and have each of you write down a dream. Associate freely to either dream. You will likely find that it is hard to associate to the dream of your friend and relatively easy to form associations to your own dream. Indeed, to the short Irma injection dream, Freud is able to associate pages and pages of memories which are cued by the different words and pictures of in his dream. Two pieces of experimental evidence exist of the individual character of dreams: subjects associating to their own dreams show more uneasiness than when associating to somebody else’s dream (Kohler and Borchers (1996)) and in an experiment by Mazzoni and Loftus (1994) it was found that words from subjects' dreams were readily recognized and remembered as having been on a particular list (which they had not been).

\section{EXECUTIVE INTERPRETATION FACILITY}

The Executive Interpretation Facility back-transforms the low level memories in the LTMS to acceptable recalls. It is not simply be the reverse of the Storage Transformation, since the Storage Transformation is a many-to-one, not a one-to-one, mapping of events and stored memories. The one-to- 
many reverse mapping must be subject to conditions of the surrounding, it must be "reality tested" by the Executive Interpretation Facility before it can be used when communicating with others. The Executive Interpretation Facility needs the context provided by current thoughts and perceptions to form an acceptable recall. Accordingly Executive Interpretation Facility communicates with the LTMS and the current perceptions and thoughts until a collection of stored memories is obtained consistent with the current perceptions and thoughts. Different contexts allows the Executive Interpretation Facility report different memories, which is consistent with the fact that recognition is different from recall and with results of memory suggestion experiments such as the ones of Loftus \& Loftus. It is also consistent with differences in memory retrievals during storage and retrieval under drunk vs. sober conditions and happy vs. sad conditions.

Freud makes several observations consistent with the existence of an Executive Interpretation Facility. For example, he writes that there is a difference between awake mentation and dreams: "we appear not to think but to experience" in dreams and also quotes Burdach (1838): "Sleep signifies an end of the authority of the self ... the images that accompany sleep can occur only on condition that the authority of the self is reduced" (p. 83) and claims "everything that appears in dreams as the ostensible activity of the function of judgement is to be regarded not as an intellectual". A relative absence of an Executive Interpretation Facility in dreams has been documented: Kahan (1994) finds that 60\% are completely unaware of dreaming while in a dream, and that $46 \%$ were completely unaware of controlling any aspect of the dream experience. Kahan and LaBerge (1996) find that while there is no categorical difference between metacognition in dreams and waking life, making choices is about half as common in dreams as in waking life. Kahan, LaBerge, Levitan and Zimbardo (1997) replicated that choices are less common in dreams than in waking life and so is event-unrelated self-reflection. Feinberg and March (1995) similarly writes that "the associative responses to ... [the mental activity in sleep] are more or less degraded, as important integrative controls are absent."

Certain features of our experience should be similar both when reported in dreams and through the Executive Interpretation Facility. These should be features easy to count and distinctive enough not to be easily associated with others ("distinctive topology"). If we believe that the LTMS is set in childhood, the features should be distinctive enough to children. One such feature may be the existence of a person and the gender of that person. There seems to be some evidence that the ratio of male to female characters in dreams is similar to the ratio among waking-life social contacts (Schredl, M., Lossnitzer, T., Vetter, S. (1998)). 
The physical identity of this Executive Interpretation Facility is unknown but it has been suggested by Feinberg and March (1995) that the difference between dream mentation and conscious mentation is corollary discharge.

\section{THE PROGRESSION OF DREAMS--THE CONSCIOUSNESS POINTER}

If dreams are excitations of the LTMS, something must be limiting our consciousness to a single dream thread because even in the most complex dreams there are not a great multitude of simultaneous locations, people or things. This brings to mind the electrode of Penfield and Rasmussen, which was limited in its spatial dimension and its effects. It seems reasonable to postulate the existence of an abstract object, a "Consciousness Pointer" (CP). The CP is similar to what Freud calls "consciousness ... a sense organ which perceives data that arise elsewhere” (p. 178). During awake times this pointer is controlled by the Executive Interpretation Facility. During sleep our control over it may be limited and once the CP starts a dream by attaching itself to a memory location., the probability of attachment elsewhere is governed by properties of the LTMS rather than controlled by the Executive Interpretation Facility. Since dreams do have associative stability (for a quantitative investigation see Rittenhouse et al (1994)) with scene changes that separate relatively stable situations from each other, the laws of the CP must include that it drifts from one memory location to another in a process that favors locations that have experienced recent changes, and are closely associated either spatially or contentwise ("sense-making," for example by preserving the self or other people in the dream).

\section{EXPERIMENTAL DISPROOFS}

There should be a strong similarity between background thought content while awake (last thoughts repeated) and as reported in dreams. Research in the former combined with existing findings in the latter could disprove the present theory.

Priming experiments (see review article by Neely (1991)) can provide a crude map of our memory structure. This map should be the same as the LTMS as revealed by dreams. Any other experiments comparing the low level structure of memory to dreams would also potentially invalidate the present theory. 


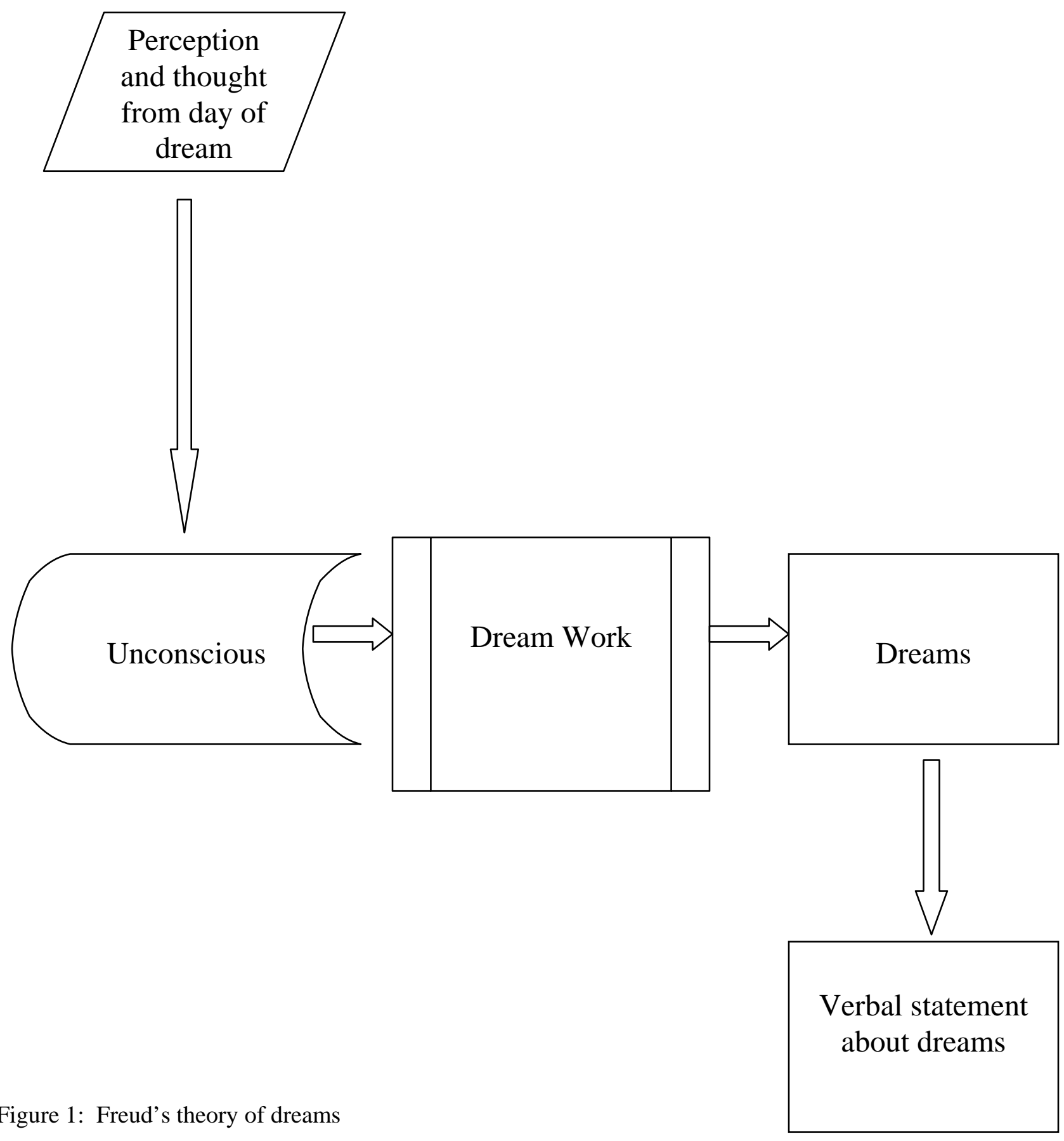




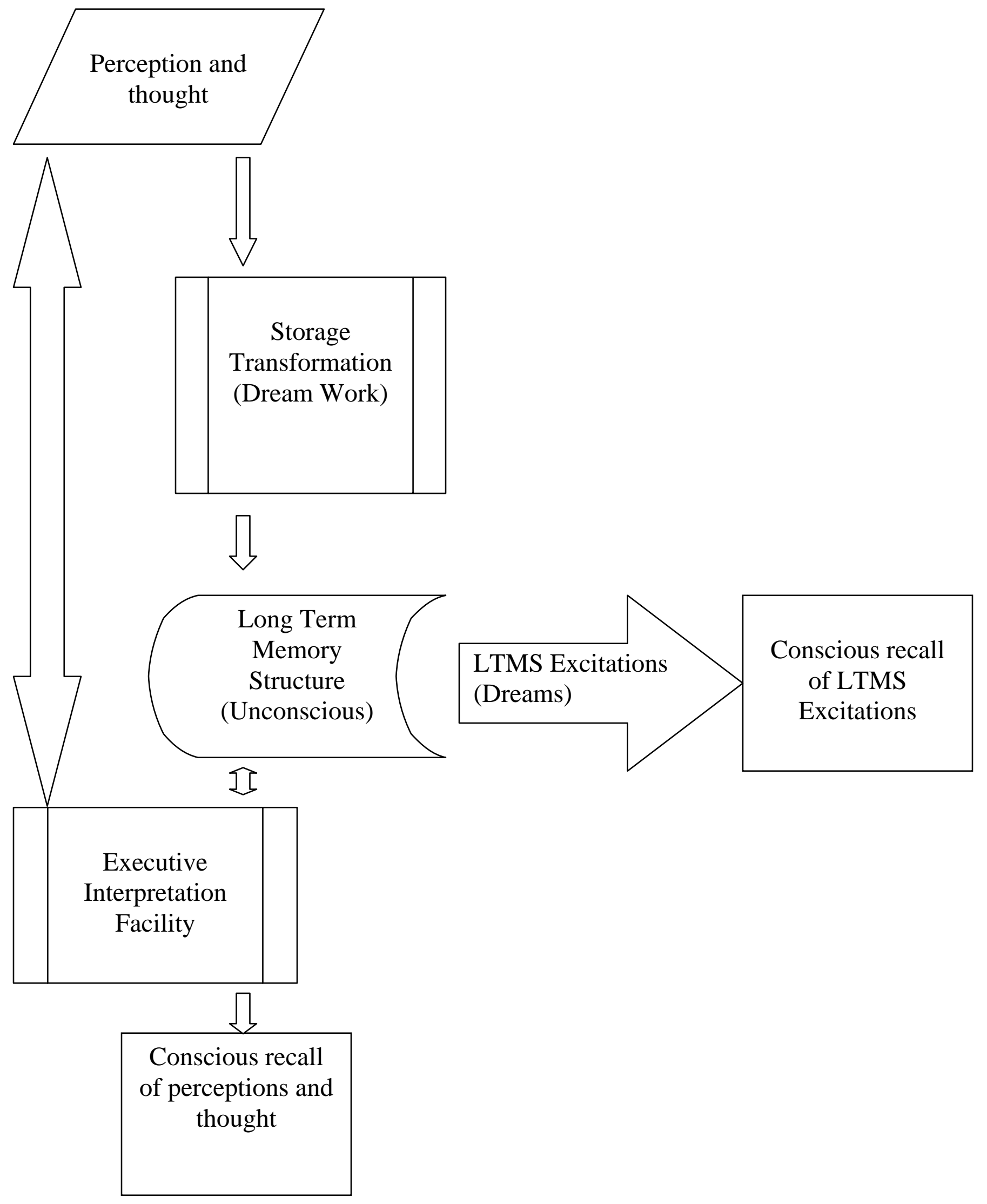

Figure 2: My theory of dreams and memory 


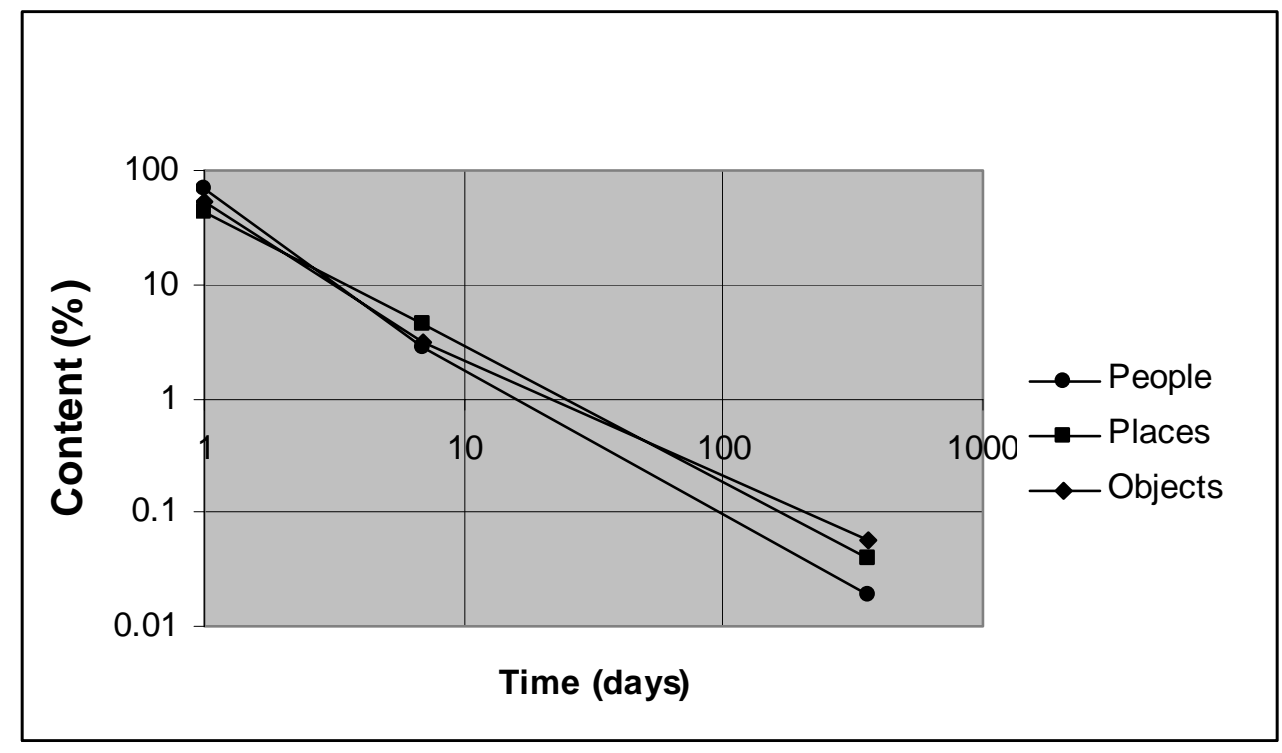

Fig. 3. The age of dream elements. 


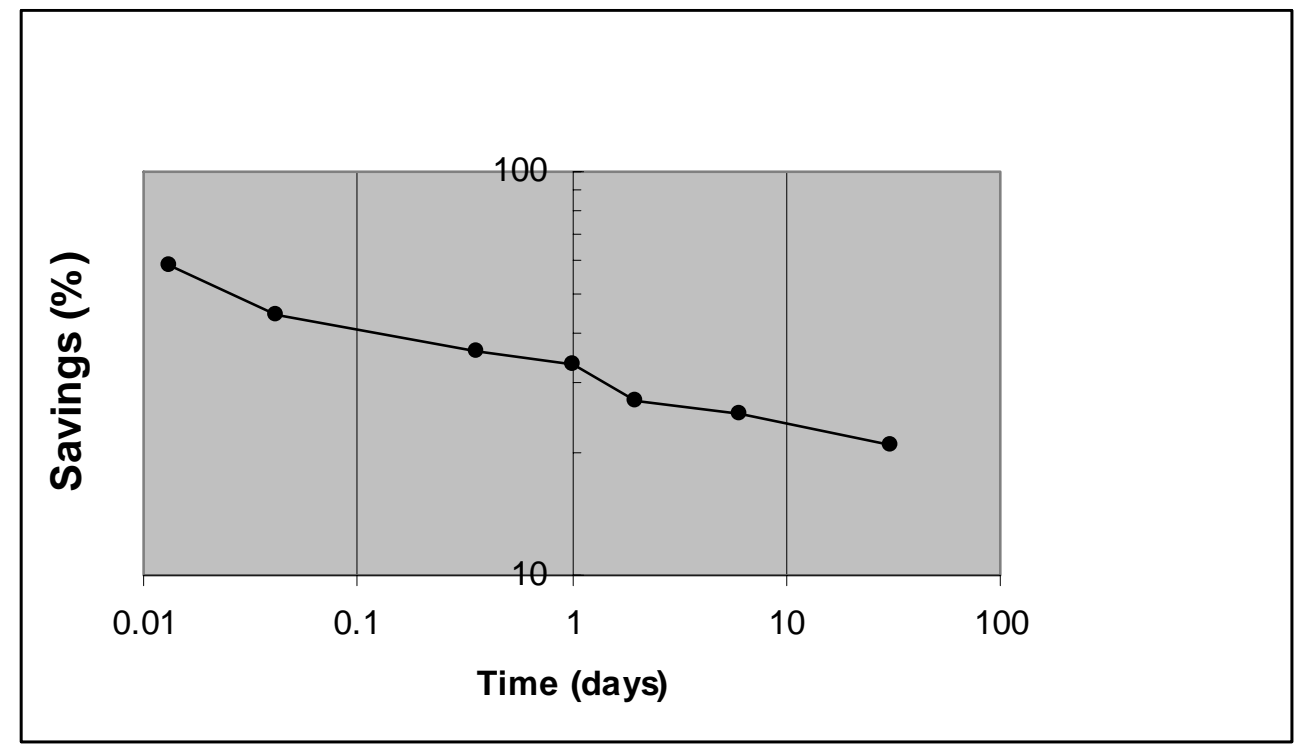

Fig. 4. Ebbinghaus time savings data. 


\section{REFERENCES}

Breger, L. (1967). "Function of Dreams." Journal of Abnormal Psychology Monograph 72, p. 128.

Cicogna, Piercarla; Cavallero, Corrado; Bosinelli, Marino. (1986). "Differential access to memory traces in the production of mental experience." International Journal of Psychophysiology, v4(n3):209-216.

Coon, D. (1991). Essentials of Psychology. St. Paul: Ist Publishing Company.

Ebbinghaus, H.E.. (1964 (orig. 1885)). Memory: A contribution to experimental psychology. New York: Dover.

Feinberg, I., March, J.D. (1995). "Observations On Delta Homeostasis, The One-Stimulus Model Of NREM-REM Alternation And The Neurobiologic Implications Of Experimental Dream Studies." Behavioural Brain Research, v69 pp97-108.

Foulkes, D., and Fliesher, S. (1975). "Mental Activity in Relaxed Wakefulness. Journal of Abnormal Psychology 84, p. 66-75.

Foulkes, D. (1993). Data constraints on theorizing about dream function. In The functions of dreaming. Ed. By A. Moffitt, M. Kramer, R. Hoffmann. Albany, New York: State University of New York Press. P. 11-20.

Freud, S. (1900). The Interpretation of Dreams. Ed. in 1965. Avon Books: New York, N.Y.

Harlow, J. and Roll, S. (1992). "Frequency of day residue in dreams of young adults.” Percept Mot Skills 74(3 Pt 1):832-4.

Kahan, T.L. (1994). "Measuring dream self-reflectiveness: a comparison of two approaches" Dreaming 4(3): 177-193.

Kahan, T.L. and LaBerge, S. (1996). "Cognition and metacognition in dreaming and waking: comoparisons of first and third-person ratings”, Dreaming 6(4): 235-249.

Kahan, T.L., Laberge, S., Levitan, L. Zimbardo, P. (1997). "Similarities and differences between dreaming and waking cognition: an exploratory study.” Consciousness and Cognition 6(1). 132-47.

Kohler, T., Borchers, H. (1996). "Experimental psychological evaluation of Freud's dream theory,” Psychotherapie, Psychosomatik, Medizinische Psychologie 46(12):419-22.

Leichtman, Michelle D.; Ceci, Stephen J.; Ornstein, Peter A. (1992). "The influence of affect on memory: Mechanism and development." IN: The handbook of emotion and memory: Research and theory. Sven-Ake Christianson, Ed; et al. Lawrence Erlbaum Associates, Inc, Hillsdale, NJ; p. 181-199.

Loftus, E. and Loftus, G (1980). “On the Permanence of stored information in the human brain.” Amer. Psychologist 35(5): 409-420. 
Mazzoni, G., Loftus, E. (1994). "When Dreams Become Reality." Consciousness \& Cognition, v5(4), pp. 442-462.

Neath, Ian (1998). Human Memory: An Introduction to Research, Data, and Theory. Pacific Grove, California: Brooks/Cole Publishing Company.

Neely, J.H. (1991). "Semantic priming effects in visual word recognition: a selective review of current findings and theories." In Besner, D. \& Humphreys, G.W. (eds). Basic Processes in Reading: Visual Word Recognition, Hillsdale, NJ: Erlbaum, 264-336.

Penfield, W. and Rasmussen, T. (1950). The Cerebral Cortex of Man. New York: Hafner Publishing Company.

Pressley, Michael. (1982). "Elaboration and memory development.” Child Development, Apr, v53 (n2):296-309.

Rittenhouse, Cynthia D.; Stickgold, Robert; Hobson, J. Allan. (1994). “Constraint on the transformation of characters, objects, and settings in dream reports.” Consciousness \& Cognition: An International Journal, Mar, v3 (n1):100-113.

Rosenlicht, N., Maloney, T. Feinberg, I. (1994). "Dream Report Length Is More Dependent On Arousal Level Than Prior REM Duration." Brain Research Bulletin, v32 (n2) pp. 99-101.

Rubin, D.C., Hinton, S., Wenzel, A. (1999) "The Precise Time Course of Retention," Journal of Experimental Psychology: Learning, Memory and Cognition 25, 1161-1176.

Schredl, M., Lossnitzer, T., and Vetter, S. (1998). "Is the ratio of male and female dream characters related to the waking-life pattern of social contacts?” Perceptual and Motor Skills 87(2) 513-4.

Schredl, M., Morlock, M., Bozzer, A. (1996). “Childhood memories and adult dreams.” Zeitschrift fur Psychosomatische Medizin und Psychoanalyse;42(1):25-33.

Solms, Mark. (1999) "Towards an integration of psychoanalysis and the neurosciences: Part 2: Syndromanalysis of psychic functions. Zur Integration von Psychoanalyse und Neurowissenschaften: Teil 2: Die Syndromanalyse..." Forum der Psychoanalyse: Zeitschrift fuer Klinische Theorie \& Praxis, v15 (n1):58-70.

Solms, Mark. (1997a) "What is consciousness?" Journal of the American Psychoanalytic Association, v45 (n3):681-703.

Solms, Mark. (1995) "New findings on the neurological organization of dreaming: Implications for psychoanalysis." Psychoanalytic Quarterly, v64 (n1):43-67.

Solms, Mark. (1997b) "The neuropsychology of dreams: A clinico-anatomical study." Lawrence Erlbaum Associates, Inc., Publishers, Mahwah, NJ, USA. 
Squire, L.R., Cohen, N. (1979). "Memory and amnesia: resistance to disruption develops for years after learning.” Behav. Neur. Biol. 25: 118.

Squire, L.R. (1987) “Memory and Brain” Oxford Press.

Strauch, I. And Meier, B. (1996) "In Search of Dreams: Results of Experimental Dream Research”. Albany, New York: State University of New York Press.

Zadra, A.L., Nielsen, T.A. (1997). “Typical dreams: a comparison of 1958 versus 1996 student samples.” Sleep Research 26: 280. 